\title{
Mechanism of gypsum hardening
}

\author{
Victoria Petropavlovskaya ${ }^{1}$, Tatiana Novichenkova ${ }^{1}$, Andrey Pustovgar $^{* 2,3}$, Aleksandr \\ Buryanov $^{2}$ and Kirill Petropavlovskii ${ }^{2}$ \\ ${ }^{1}$ The Tver State Technical University, Tver, Russia, \\ ${ }^{2}$ Moscow State University of Civil Engineering, Yaroslavskoye Shosse, 26 , Moscow, 129337, Russia \\ ${ }^{3}$ Science Center for Nonlinear Wave Mechanics and Technology, Institute of Machine Science, \\ Russian Academy of Sciences, (NTs NVMT IMASh), Moscow, Russia
}

\begin{abstract}
In the present work the receiving of gypsum products on the basis of a calcium sulfate dihydrate is described. As a raw material, the calcium sulfate dihydrate in the form of industry waste was used. This research offers the mechanism of un hydration hardening of monomineral bindings, including gypsum. The mechanism is based on interaction of particles of the different size in the conditions of supersaturation when pressing. Under the corresponding conditions in system of a dihydrate crystallizational contacts are formed. The offered mechanism is confirmed with pilot studies. Researches of solubility of powders, to deformations of raw mix, strength, density and other characteristics of structure are conducted. Strength reaches to $74 \mathrm{MPa}$. The way allows to simplify technology of receiving gypsum products. Expenses of energy decrease. Burn is excluded and the grinding is reduced. Thus the offered of un hydration hardening of monomineral binders has high innovative appeal.
\end{abstract}

\section{Introduction}

A. Polak proposed the preparation of a material from calcium sulfate dihydrate. [1-3]. In the technology pressing of suspension with use of filters was used.

V. Jung investigated powders of rocks. He has shown that they can create strong structure. Most intensively harden - the gypsum stone and marble $[2,4]$.

Such ways are difficult [4]. They demand a large amount of energy on grind, additional difficult technological stages.

In this work the different way is offered. The phase contact is formed between large and small particles of a dihydrate [5]. For this purpose it is necessary to support extent of supersaturation and mechanical force in system of a calcium sulfate dihydrate [5]. The ratio of supersaturation and force has to be optimum. Crystals of gypsum keep in the situation defined, fixed rather each other. Such efforts can be a consequence of pressure which is enclosed from the outside. Or - by crystallizational pressure. It develops in the course of growth of crystals in a framework at structure formation $[5,6]$. Water in thin layer on a surface of particles forms solution [7]. Its concentration depends on the size of particles and distance from a layer surface $[4,6]$. At rapprochement of particles solution layers at a

\footnotetext{
* Corresponding author: PustovgarAP@mgsu.ru
} 
surface of particles are blocked. There are conditions for formation of contacts $[6,8]$. Process of condensation of the dissolved substance happens in places of the maximum negative curvature. Solid substance in the active centers is condensed spontaneously, without energy expenses [6,8]. Process is defined: grain structure $[9,10,11]$, chemical composition [12], level $\mathrm{pH}$ [13-15], external conditions - temperature and humidity [16] and other parameters (Figure 3).

Use of hyper pressing and optimum grain structure allows to simplify process of receiving gypsum products considerably. There are conditions for formation of contacts [18]. Process of condensation happens in places of the maximum negative curvature. Solid substance is condensed spontaneously, without expenses of energy [19]. In these researches high strength is provided with low excess concentration.

The grain composition of mix defines extent of supersaturation, the area and the quantity of contacts. The offered way is confirmed with researches on solubility of the dihydrate powders, strength of structure, on deformations of raw mix.

\section{Materials and methods}

In researches the calcium sulfate dihydrate - industry waste was used. In work mixes from powders of different extent of grind were applied. Powders have been received by preliminary crushing on a crusher and a grind in a laboratory mill. The grain structure was defined on the laser analyzer of particles (Figure 1).

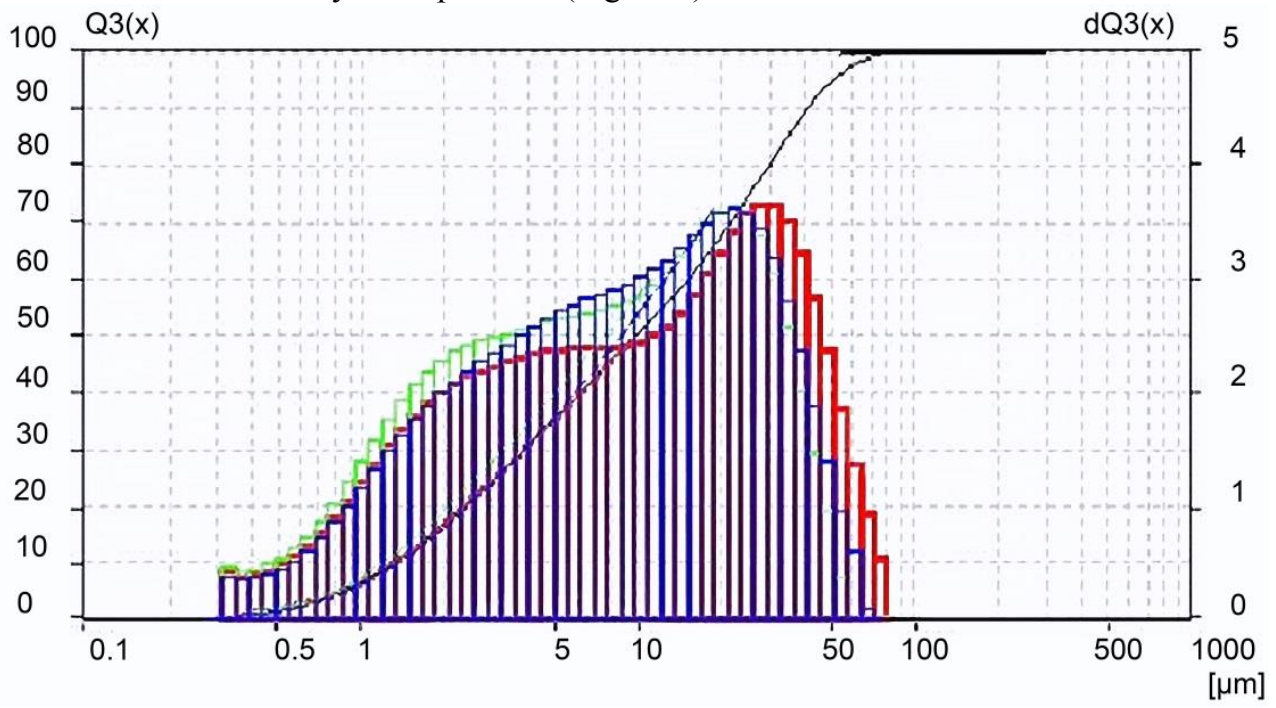

Fig.1. Histograms of grain structure of a calcium sulfate dihydrate of the different composition

Solubility of gypsum mixes was defined on the conductometer (Figure 2). Measurements were taken every 10 minutes within 1 hour. The assessment of influence of grain structure on properties was carried out on samples cylinders $0.05 \times 0.05 \mathrm{~m}$. They were pressed from moist mix and tested for the 28th days. Curing of gypsum samples was carried out at a normal temperature in a desiccator at humidity of the environment of more $\mathrm{W}=95$ $\%$ and in normal dry air conditions according to the program of researches.

Strength of the pressed materials on the basis of a calcium sulfate dihydrate was defined by standard methods on samples-cylinders of $0.05 \times 0.05 \mathrm{~m}$ in size; samples-prisms of 0.04 $\mathrm{x} 0.04 \mathrm{x} 0.16 \mathrm{~m}$ in size.

Strain characteristics of gypsum powdery raw mixes were determined by an original 
technique (the return average strength, elastic expansion). She was offered by I. Berney and V. Belov. The POFS-1 device has been developed for a research of forming properties of ceramic powders (The Tver state technical university) [17]. It is applicable for pressing of powder mixes of a calcium sulfate dihydrate.

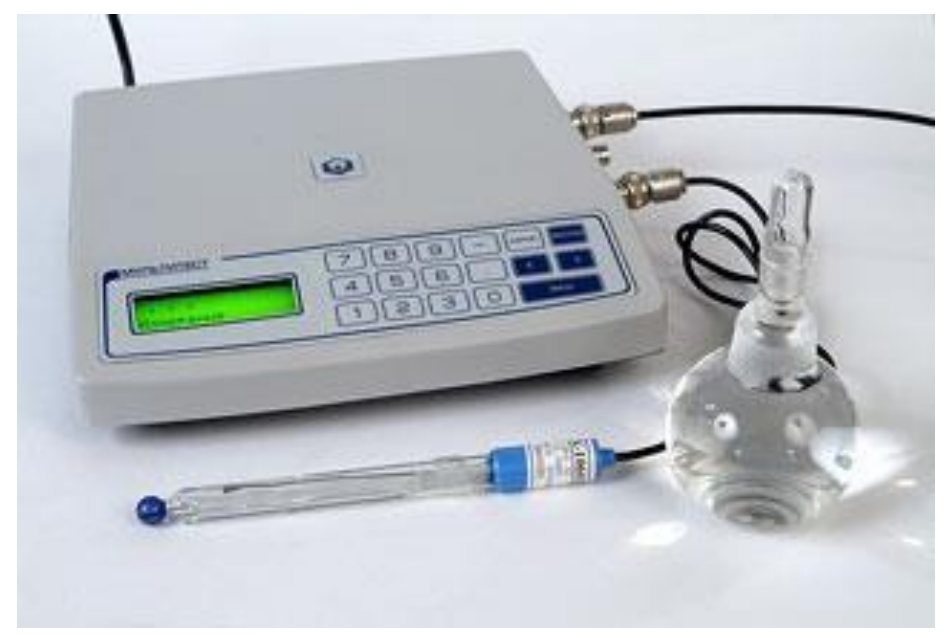

Fig. 2. Conductivity apparatus «Multitest KSL-101»

\section{Results and discussion}

Experimental confirmation of the offered mechanism has been carried out.

Dependences were investigated: of solubilities of the calcium sulfate dihydrate powders mix from quantity of particles of a mesh size in mix, deformation when pressing a raw stock from ratio water/binder, strength of gypsum stone structure from the hardening conditions.

Results of solubility researches of the calcium sulfate dihydrate showed, that force of solubility depends on grain structure (Figure 4).

When interfusing "monogranularity" average solution strength depends on the maintenance of separate "mono granularity" and has a deviation from calculated values. The greatest deviations are characteristic of mixes which support 50- $75 \%$ of shallow "mono granularity". At best values conditions for emergence of waterproof contacts in system $[15,16]$ are created.

Strength of exemplars of the best structure in 2 hours makes $50 \%$ of their strength at the age of 28 days. For the 28th days strength reaches from 40 to $74 \mathrm{MPa}$ (Figure 5).

Resistance to consolidation speaks about existence of a large quantity of contacts between particles of forming mix. Therefore, forming properties of gypsum powder determine strength of structure of the disperse system. By the received results the greatest resilient expansion 0.0175 of $\mathrm{cm}^{2} / \mathrm{g}$ is reached at the "water / solid" relation -0.24 . At change of the ratio «water / solid» resilient expansion decreases (Figure 6). 


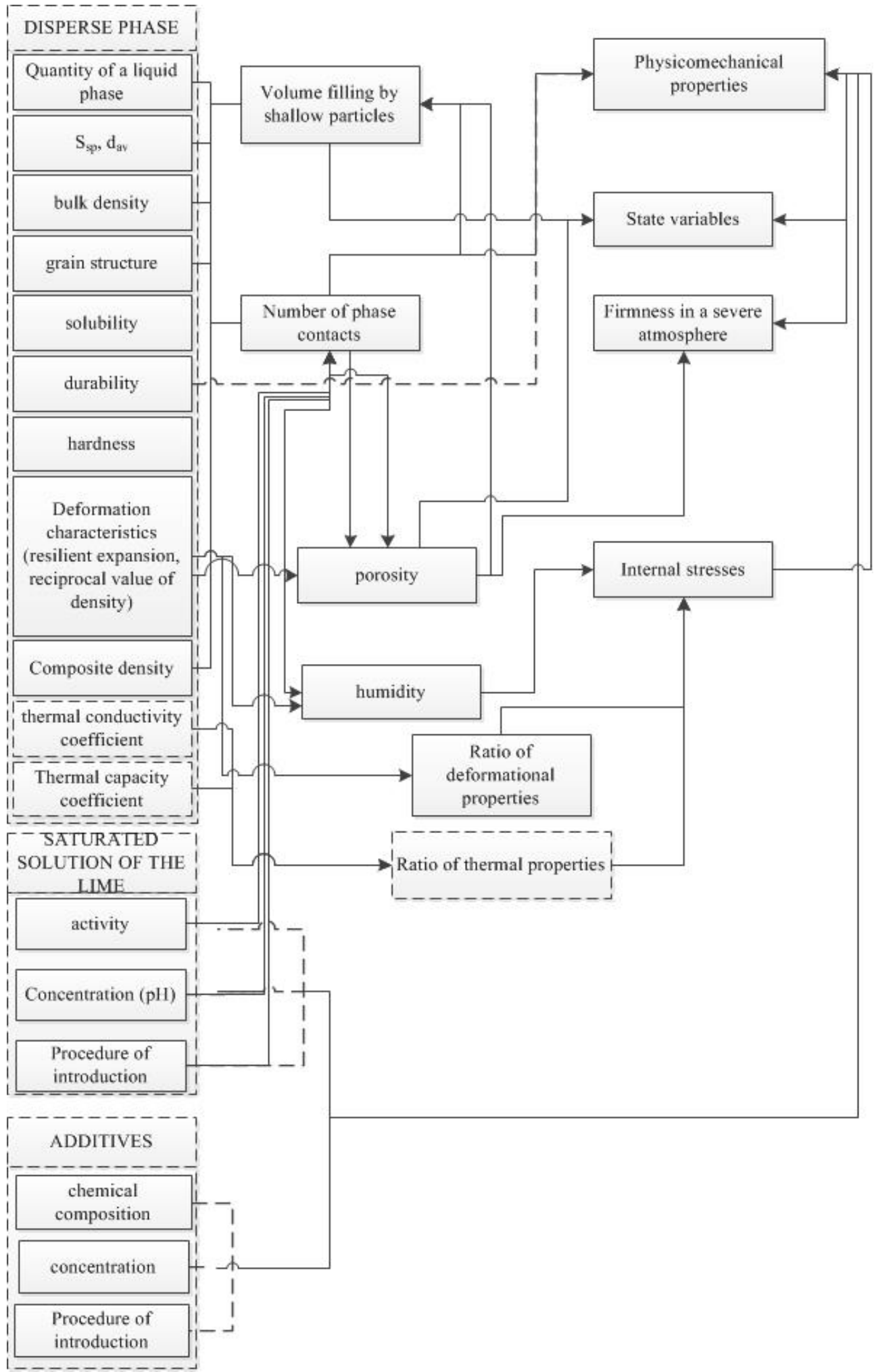

Fig. 3. Criteria of optimization at un hydration hardening 


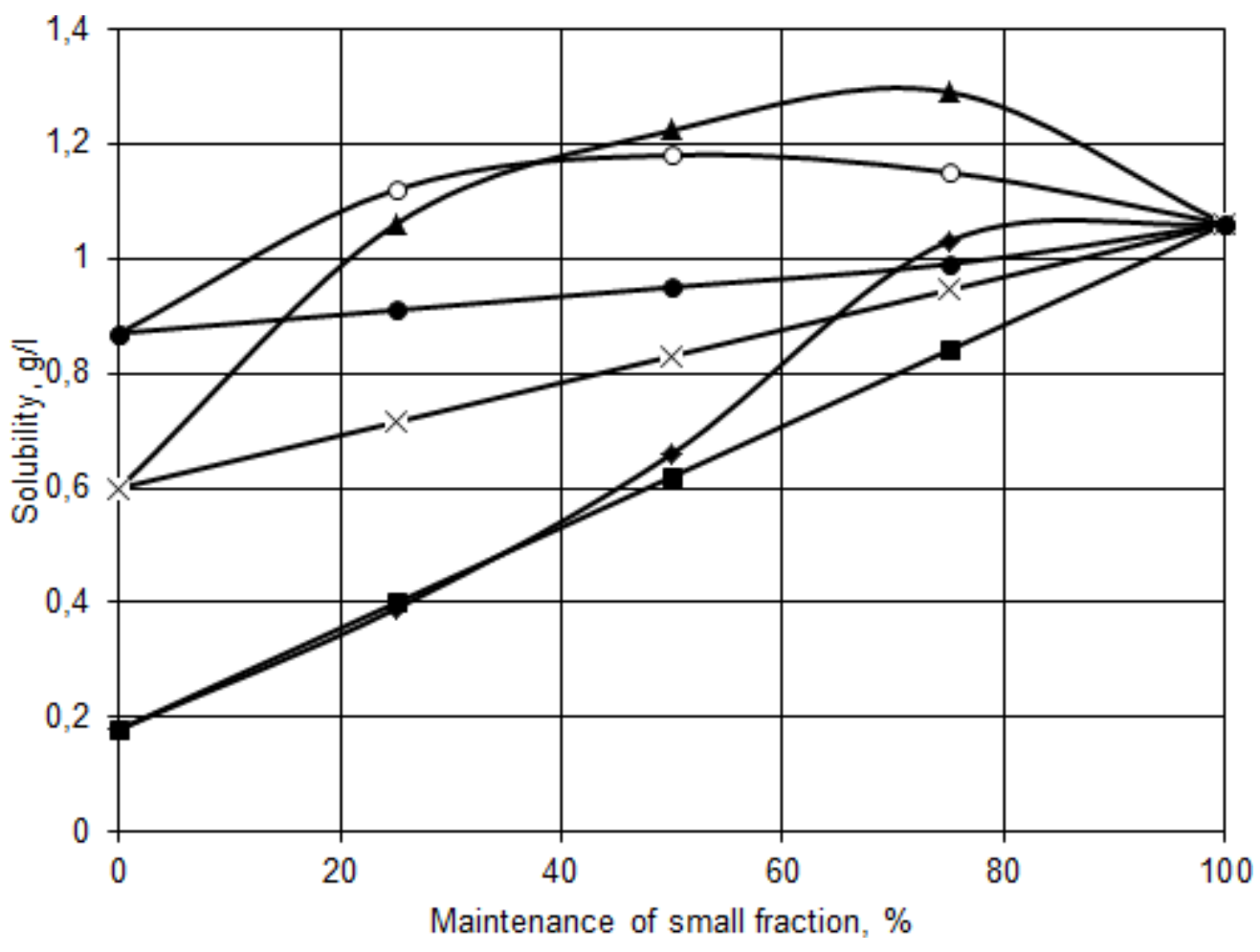

Fig. 4. Dependence of solubility of mixes of powders of the calcium sulfate dihydrate on grain composition:

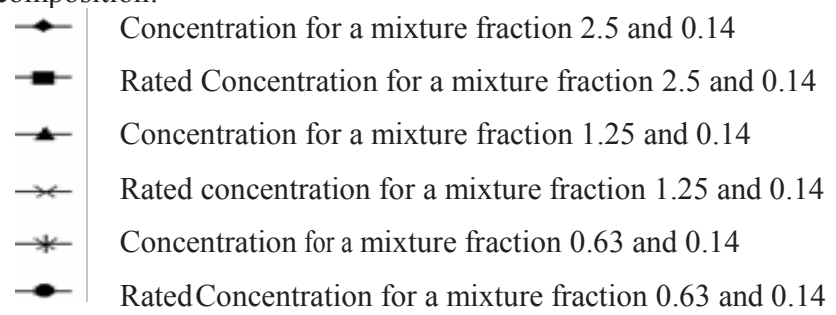

When interfusing "mono granularity" average solution strength depends on the maintenance of separate "mono granularity" and has a deviation from calculated values. The greatest deviations are characteristic of mixes which support 50-75\% of shallow "mono granularity". At best values conditions for emergence of waterproof contacts in system [18] are created.

Strength of exemplars of the best structure in 2 hours makes $50 \%$ of their strength at the age of 28 days. For the 28 th days strength reaches from 40 to $74 \mathrm{MPa}$ (Figure 5). 


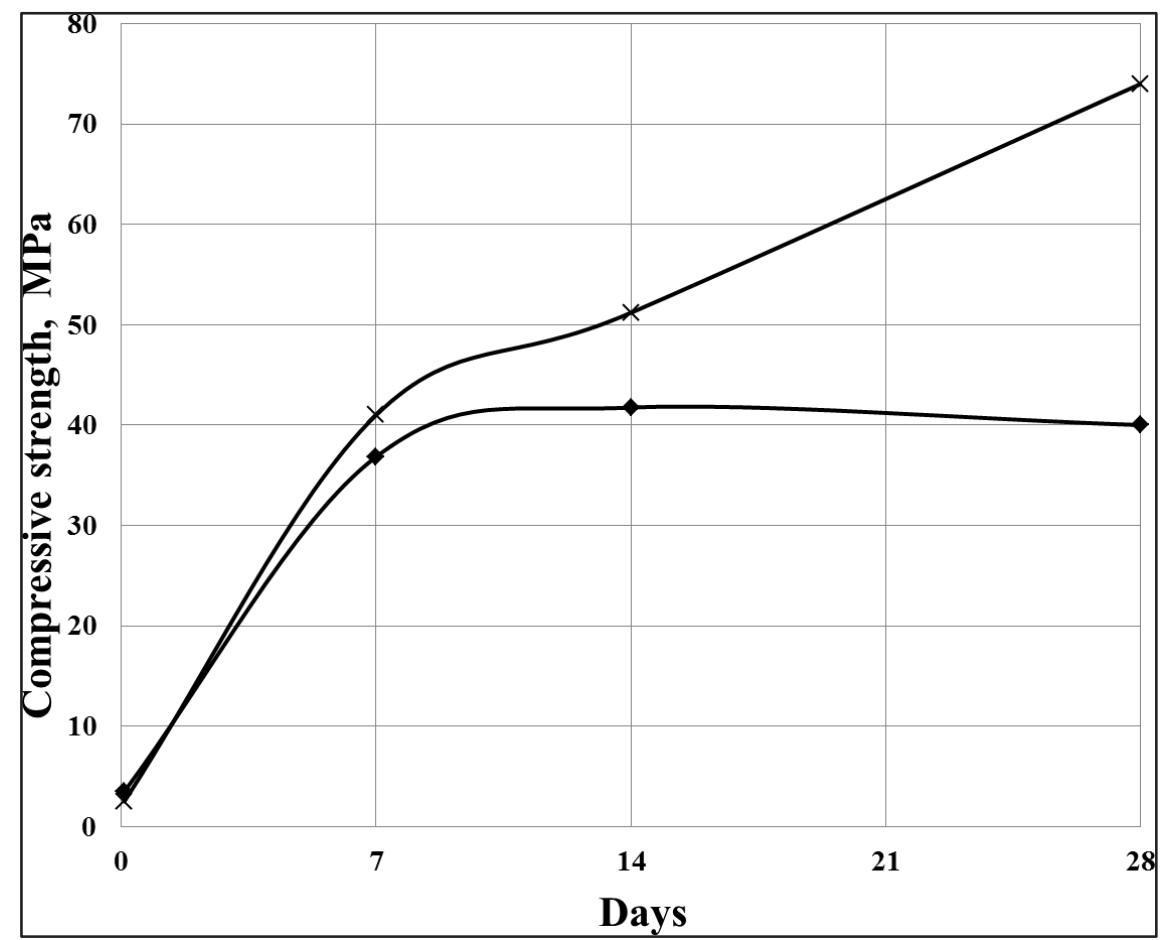

Fig.5. Dependence of strength of gypsum composites on concreting conditions:

$\mathrm{x}$ - air - dry conditions

- air - the wet conditions

Resistance to consolidation speaks about existence of a large quantity of contacts between particles of forming mix. Therefore, forming properties of gypsum powder determine strength of the disperse system structure. By the received results the greatest resilient expansion 0.0175 of $\mathrm{cm}^{2} / \mathrm{g}$ is reached at the "water / solid" relation -0.24 . At change of the «water / solid» relation resilient expansion decreases (Figure 6).

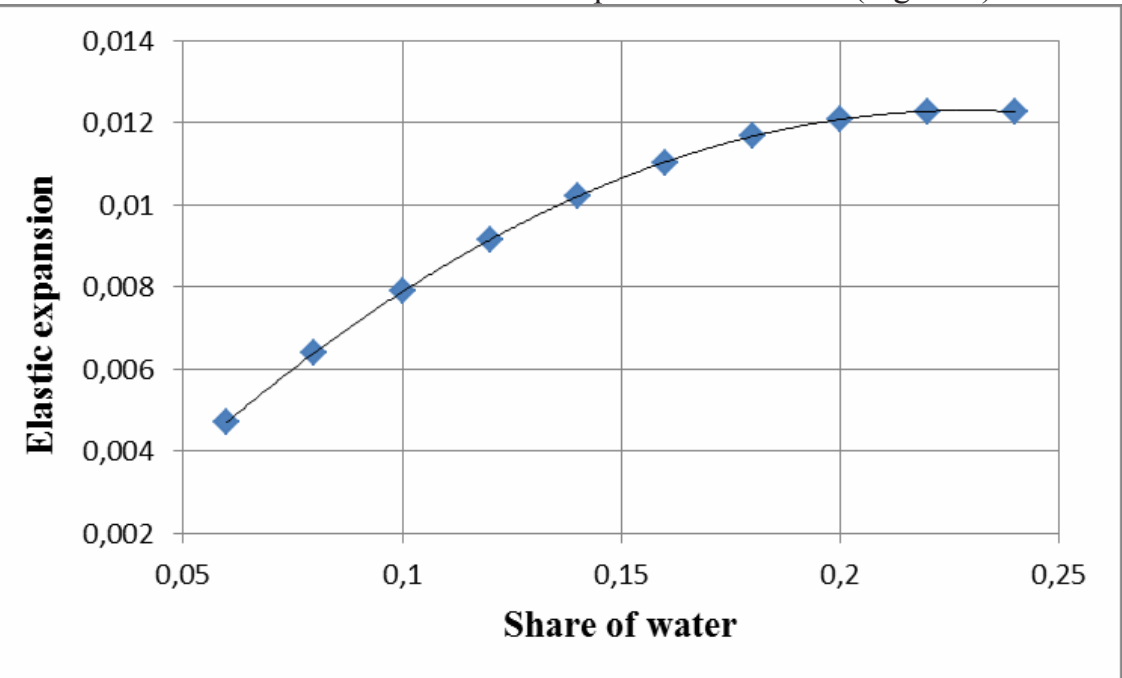

Fig. 6. Dependence elastic expansion from share of water 


\section{Conclusions}

Results of researches of solubility and strength from grain structure have coordinated with theoretical provisions. Selection of optimum grain ratio of mixture of raw materials according to the offered mechanism influences solubility and terminating strength of the gypsum stone. Strength increases in more than by $100 \%$.

The offered mechanism allows to simplify technology. It makes it more available for production of gypsum constructions. Gypsum products receive from a gypsum stone. Burn of the gypsum is excluded. At the operating and designed enterprises of structural materials may be produce. Energy consumptions decrease. The grind is reduced. Introduction of powder of coarse grind reduces energy consumptions on a refinement. It increases production efficiency.

\section{References}

1. A.F. Polak, Curing of the monomineral binders, (Moscow, Stroyizdat, 1966)

2. A.F. Polak, About formation possibility structures on the basis of dehydrate of sulphate of calcium, Izvestija vuzov. Stroitel'stvo, 10, (1987)

3. V.V. Babkov, Modified gypsum with increased water resistance and gypsum expanded-clay concrete wall blocks for low housing construction, third ed., Stroitel'nye materialy, (2012)

4. V.B. Petropavlovskaya, V.V. Belov, T.B. Novichenkova, Maloenergoemkie gipsovye stroitel'nye kompozity [Low power gypsum building composites], (Tver, TvGTU, 2014)

5. P. A. Rehbinder, E. E. Segalova, E. A. Amelina, and et al, Physical and chemical bases of hydration curing of the binders, The sixth international congress in cement chemistry, (Moscow, Stroyizdat, 1976)

6. V.B. Petropavlovskaya, T. B. Novichenkova, A.F. Buryanov, and et al, Procedia Engineering 57, pp. $906-913$, (2013)

7. G. A. Akselrud, A. D. Molchanov, Dissolution of solid substances, (Moscow, Chemistry, 1977)

8. V.B. Petropavlovskaya, A.F. Buryanov, T. B. Novichenkova, Maloehnergoemkie gipsovye materialy $i$ izdeliya na osnove othodov promyshlennosti, Stroitel'nye materialy, 7 (2012)

9. V.S. Lesovik, N.V. Chernysheva, V.G. Klimenko, Structurization processes of the gipsum-containing components considering raw materials genesis, Izvestija vuzov. Stroitel'stvo, (2012)

10. S. Leontev, K. Saraykina, V. Golubev, L. Urkhanova, Influence of ultra- and nanodisperse size additives on the structure and properties of heat insulating autoclaved aerated concrete, Procedia Engineering, pp. 649-656, (2017)

11. V. G. Babayev, V. V. Strokova, V. V. Nelyubova, Vestnik Belgorodskogo gosudarstvennogo universiteta imeni V. G. Shukhova: BGTU, 4, (2012)

12. M.S. Garkavi, Structure formation of nanomodified gypsumpolimer material, third ed., Suhie stroitel'nye smesi, (2013)

13. V. Petropavlovskaya, A. Buryanov, T. Novichenkova, Advanced Materials Research, 467, pp. 91-96, (2014)

14. V.V. Belov, A.F. Bur'janov, G.I. Jakovlev, V.B. Petropavlovskaja, H.-B. Fisher, I.S. Maeva, T.B. Novichenkova, Modification of structure and properties of construction composites based on calcium sulfate, (Moscow, De Nova, 2012)

15. V. Petropavlovskaya, A. Buryanov, T. Novichenkova, Advanced Materials Research, 1025 - 1026 (2014) 
16. V. Petropavlovskaya, V. Belov, T. Novichenkova, A. Buryanov, etc. Use of waste of the natural gypsum stone in production of unburning materials, Stroitel'nye Materialy, 7 (2014)

17. I. I. Berney, V. V. Belov, The device for definition of forming properties of ceramic powders, Patent 140834 USSR.

18. V. Petropavlovskaya, A. Buryanov, T. Novichenkova, Advanced Materials Research, 941-944 (2014)

19. A.O. Adamtsevich, S.A. Pashkevich, A.P. Pustovgar, Application of calorimetry for prognosticating strength increase of fast-curing cement systems, Magazine of Civil Engineering, 38 (3), pp. 36-42, (2013) 